\title{
Peningkatan Kompetensi Guru dalam Mengimlementasikan Kurikulum 2013 Dalam Education 4.0
}

\author{
Hotmaulina Sihotang ${ }^{1}$; Mesta Limbong ${ }^{2}$; Bintang R. Simbolon ${ }^{3}$; Hotner \\ Tampubolon $^{4}$, Marina Silalahi ${ }^{5}$ \\ Universitas Kristen Indonesia, Jakarta, Indonesia ${ }^{1,2,3,4,5}$ \\ E-mail: hotmaulina.sihotang@uki.ac.id
}

\begin{abstract}
Abstrak
Pengabdian kepada masyarakat merupakan bagian integral tri dharma perguruan tinggi yang melibatkan dosen, mahasiswa, dan tenaga kependidikan. Pengabdian kepada masyarakat bertujuan memberikan makna kebermanfaatan keberadaan Program Magister Administrasi Pendidikan kepada sekolah Kasih Immanuel dalam meningkatkan kompetensi mengimplementasikan kurikulum 2013. Populasi seluruh guru SD, SMP, SMA Kasih Immanuel sebanyak 15 orang dan sampel penelitian seluruh guru, namun yang hadir 12 orang. Data diperoleh dengan wawancara mendalam terhadap kepala sekolah dan guru. Selain itu data diperoleh melalui instrumen pre test dan post test. Data dianalisis menggunakan statistik deskriptif. Hasil pengabdian kepada masyarakat menunjukkan: (1) Guru mengajar merangkap di SD, SMP, dan SMA, (2) Guru yang memenuhi standar kualifikasi pendidikan 50\%, (3) Guru yang sudah tersertifikasi $25 \%$, dan (4) Pemberian bimbingan teknis implementasi kurikulum 2013 sangat bermanfaat meningkatkan kompetensi pedagogik, personal, sosial dan profesional. Implikasi pengabdian kepada masyarakat guru semakin termotivasi melengkapi rencana pelaksanaan pembelajaran (RPP) dan meningkatkan profesionalitas guru.
\end{abstract}

Kata kunci: Kompetensi, implementasi, Kurikulum 2013

\begin{abstract}
Community service is an integral part of the three pillars of higher education that involves lecturers, students, and education staff. Community service aims to give meaning to the usefulness of the existence of the Educational Administration, graduate Program Universitas Kristen Indonesia to the Kasih Immanuel school in improving the competence of implementing the 2013 curriculum. The population of all elementary school, junior high school students is Kasih Immanuel as many as 15 people and a sample of all teachers, but there are 12 people present. Data obtained by in-depth interviews with principals and teachers. In addition, data were obtained through pre-test and post-test instruments. Data were analyzed using descriptive statistics. The results of community service show: (1) Teachers teaching concurrently in elementary, middle and high school, (2) Teachers who meet the $50 \%$ educational qualification standard, (3) $25 \%$ certified teachers, and (4) Providing technical implementation guidance the 2013 curriculum is very useful in increasing pedagogical, personal, social and professional. The implications of service to the teacher community are increasingly motivated to complete the lesson plan and increase teacher professionalism.
\end{abstract}

Keywords: Competence, implementation, curriculum 


\section{PENDAHULUAN}

Seiring dengan regulasi pemerintah UU No.20 tahun 2003 tentang sistem pendidikan nasional yang menyatakan standar guru minimal kualifikasi pendidikan minimal D4 atau sarjana. Masalah pendidikan secara realita masih terdapat sekolah yang memiliki guru belum sarjana. Namun setelah mereka aktif sebagai guru, kemudian ada langkah-langkah memenuhi standar tersebut. Misalnya para guru yang masih under-standard tadi melakukan upaya sungguh-sungguh untuk

a. meningkatkan kualitas diri, baik dengan cara melanjutkan studi atau kegiatan lain. Untuk dapat melaksanakan tugasnya sebagai guru yang baik, pemerintah Indonesia bersama berbagai lembaga terkait telah merumuskan dan menyusun butir penting yang harus dipenuhi oleh para guru yang kemudian disebut dengan standar profesionalitas guru. Masalah standar guru belum selesai diatasi, saat ini dunia telah memasuki era revolusi industri 4.0 dan berdampak pada pendidikan sekaligus memasuki era pendidikan 4.0 (education 4.0) yang ditandai dengan meningkatnya konektivitas, interaksi serta perkembangan sistem digital, artifisial, dan virtual. Dengan semakin konvergennya batas antara manusia, mesin dan sumber daya lainnya, teknologi informasi dan komunikasi tentu berimbas pula pada berbagai sektor kehidupan termasuk pada sistem pembelajaran. Perubahan era ini tidak dapat dihindari oleh siapapun sehingga dibutuhkan penyiapan sumber daya manusia (SDM) agar siap menyesuaikan dan mampu bersaing dalam memperkenalkan dan menyiapkan peserta didik pada era education 4.0. Peningkatan kualitas SDM melalui jalur pendidikan formal mulai dari tingkat satuan pendidikan dasar (SD, SMP) dan menengah (SMA, SMK) hingga ke perguruan tinggi adalah kunci untuk mampu mengikuti perkembangan Revolusi Industri 4.0. Guru memiliki peran yang sangat strategis dalam menyiapkan kompetensi peserta didik dalam pembelajaran di sekolah dengan menggunakan model pembelajaran yang tepat agar peserta didik mampu berpikir kritis dan kreatif sesuai dengan tingkat satuan pendidikan. Guru harus mampu menyiapkan perencanaan pembelajaran, melaksanakan pembelajaran, melaksanakan evaluasi pembelajaran sehingga siswa mampu berpikir tingkat tinggi atau sering disebut higher order thinking skills/HOTS (Barak Miri, et al. 2007; Hopson, et al. 2001). 
b. Setiap lembaga pendidikan harus mempersiapkan oritentasi dan literasi baru dalam bidang pendidikan, terutama yang sangat terkait erat dengan persiapan SDM dalam menghadapi education

c. 4.0. Literasi lama yang mengandalkan baca, tulis dan hitung harus berubah dan diperkuat dengan literasi baru yaitu literasi data, teknologi dan sumber daya manusia. Literasi data adalah kemampuan untuk membaca, analisis dan menggunakan informasi dari data dalam dunia digital. Literasi teknologi adalah kemampuan untuk memahami sistem mekanika dan teknologi dalam dunia kerja. Sedangkan literasi sumber daya manusia yakni kemampuan berinteraksi dengan baik, mampu berkomunikasi, tidak kaku, dan berkarakter sesuai dengan visi dan nilainilai yang ditanamkan di sekolah. Keberhasilan untuk menghadapi era education 4.0 sangat tergantung dengan ditentukan oleh kualitas guru. Guru dituntut menguasai kompetensi sebagai pendidik, yakni kompetensi pedagogik, kompetensi personal, kompetensi interpersonal dan kompetensi profesional (UU No. 14 tahun 2015). Peraturan Pemerintah No. 74 tahun 2008 tentang Guru, pasal 3 ayat 2, seorang guru dikatakan profesional apabila memenuhi beberapa kriteria atau persyaratan kompetensi yang meliputi kompetensi pedagogik, kompetensi kepribadian, kompetensi sosial, dan kompetensi professional. Pertama, kompetensi pedagogik : (1) Menguasai karakteristik peserta didik dari aspek fisik,moral, spiritual, sosial, kultural, emosional, dan intelektual; (2) Mengidentifikasi potensi peserta didik dalam mata pelajaran yang diampu ; (3) Mengidentifikasi bekal-ajar awal peserta didik dalam mata pelajaran yang diampu; (4) Mengidentifikasi kesulitan belajar peserta didik dalam mata pelajaran yang diampu; (5)Menguasai teori belajar dan prinsip-prinsip pembelajaran yang mendidik; (6) Memahami berbagai teori belajar dan prinsip-prinsip pembelajaran yang mendidik terkait dengan mata pelajaran yang diampu ; (7) Menerapkan berbagai pendekatan, strategi, metode, dan teknik pembelajaran yang mendidik secara kreatif dalam mata pelajaran yang diampu; (8) Mengembangkan indikator dan instrumen penilaian. Kedua, kompetensi kepribadian lebih dekat dengan kompetensi afektif guru. Kompetensi kepribadian meliputi (1) Menampilkan diri sebagai pribadi yang mantap dan stabil ;(2) Menampilkan diri sebagai pribadi yang dewasa, arif dan berwibawa . (3) Menunjukkan etos kerja, (4) Tanggung jawab yang tinggi, (5) Rasa bangga menjadi guru, dan percaya diri (6) Berperilaku jujur, tegas, dan manusiawi, (7) Menjunjung tinggi kode etik profesi. Ketiga, kompetensi sosial berkaitan dengan kemampuan guru dalam masyarkat sebagai bagian dari masyarakat dengan indikator : 
berkomunikasi secara santun, (2) bergaul secara efektif dengan peserta didik, sesama pendidik, orangtua/wali, dan masyarakat luas, (3) mengindahkan norma-norma masyarakat yang berlaku, (4) beradaptasi dengam budaya, masyarakat, dan sebagainya. Keempat,

kompetensi profesional guru dituntut untuk bekerja secara lebih maksimal dalam mempersiapkan peserta didiknya guna menghadapi perubahan-perubahan zaman yang terus berkembang. Kompetensi profesional ini merupakan kemampuan dan kewenangan tugas yang harus dilakukan oleh guru dalam menjalankan profesi keguruannya. Kompetensi profesional menguasai substansi keilmuan yang terkait dengan bidang studi. Subkompetensi ini memiliki indikator esensial: memahami materi ajar yang ada dalam kurikulum sekolah; memahami struktur, konsep dan metode keilmuan yang menaungi atau koheren dengan materi ajar; memahami hubungan konsep antar mata pelajaran terkait; dan menerapkan konsep-konsep keilmuan dalam kehidupan sehari-hari; Menguasai langkah-langkah penelitian dan kajian kritis untuk menambah wawasan dan memperdalam pengetahuan/materi bidang studi. Sebagaimana diatur dalam

Permendikbud Nomor 4 Tahun 2018 tentang Penilaian Hasil Belajar oleh Satuan Pendidikan dan Penilaian Hasil Belajar oleh Pemerintah, ujian nasional (UN) yang diselenggarakan oleh pemerintah, dan ujian sekolah berstandar nasional (USBN) yang diselengarakan oleh satuan pendidikan terus menerus disempurnakan. Secara substantif peningkatan kualitas soal ujian baik ujian nasional maupun ujian sekolah berstandar nasional, yaitu dengan memasukkan secara bertahap standar High Order Thinking Skill (HOTS). Bloom dalam Cruickshank (2014) bahwa tujuan pembelajaran adalah menghasilkan siswa yang memiliki kemampuan berpikir HOTS ditunjukkan dengan kemampuan menganalisis, mengevaluasi dan mencipta. Guru dari sekolah swasta belum semua mendapatkan pelatihan implementasi Kurikulum 2013, bagaimana mengajar agar peserta didik memiliki kemampuan berpikir HOTS, menilai hasil belajar melalui USBN dan UN berstandar HOTS yang diselenggarakan pemerintah. oleh karena itu sekolah harus mengadakan upaya sendiri ditengah keterbatasnnya. Karena keterbatasan anggaran maka sekolah dapat bermitra dengan perguruan tinggi. UKI salah satu PTS melalui dharma pengabdian kepada masyarakat dapat berbagi pengetahuan dengan melakukan pelatihan guru untuk dapat membuat soal dengan standar HOTS ini. Harapannya nanti akan ditemukan keselarasan antara pengukuran capaian hasil belajar peserta didik berdasar ujian nasional dengan capaian beberapa penilaian internasional. 
Peraturan Menteri Pendidikan Nasional nomor 16 Tahun 2007 mengatur kompetensi guru untuk setiap satuan pendidikan mencakup kualifikasi akademik guru pendidikan Anak Usia Dini/Taman Kanak-kanak/Raudatul Atfal (PAUD/TK/RA), guru sekolah dasar/madrasah ibtidaiyah (SD/MI), guru sekolah menengah pertama/madrasah Tsanawiyah (SMP/MTs), guru sekolah menengah atas/madrasah aliyah (SMA/MA). Pemerintah sudah dan terus berupaya agar SDM mampu menghadapi kemajuan yang sangat cepat diantaranya dengan mengeluarkan kebijakan pada tahun TA 2019/2020 agar sekolah mengimplementasikan Kurikulum 2013 baik sekolah yang diselenggarakan pemerintah maupun sekolah yang diselenggarakan oleh masyarakat atau yayasan. Sekolah Kasih Immanuel yang diselenggarakan oleh yayasan mau tak mau harus mengikutinya.

Berdasarkan studi pendahuluan yang kami lakukan ke Sekolah Kasih Imanuel pada Kamis, 20 Juni 2019, berdasarkan wawancara yang kami lakukan terhadap kepala sekolah SD dan SMA ibu Pdt. Dr. Ir. Anike M. Salaka, MA, M.Pd bahwa guru belum semuanya memenuhi kualifikasi akademik dan kompetensi yang dipersyaratkan undang-undang. Hal ini ditunjukkan dengan baru empat orang guru dari SD, SMP, dan SMA yang telah tersertifikasi. Guru mendapatkan penghasilan masih jauh dari UMR sehingga usai menjalankan tugas harus melakukan pekerjaan lain untuk memenuhi kebutuhan. Sekolah mendapatkan biaya pendidikan dari dana BOS, bagi siswa yang memiliki kartu keluarga DKI dan dana persembahan kasih dari Yayasan. Yayasan sendiri tidak hanya membiayai pendidikan namun juga membiayai panti asuhan dan panti jompo. Siswa tidak dikenai biaya pendidikan karena siswa berasal dari keluarga yang kurang beruntung. Berdasarkan uraian diatas sekolah ini sangat tepat menjadi sasaran Program Magister Prodi Administrasi Pendidikan UKI untuk dapat membantu banyak hal untuk meningkatkan kompetensi mengajar dalam mengimplementasikan Kurikulum 2013.

\section{METODE}

Pengabdian masyarakat merupakan bagian integral tri dharma perguruan tinggi yang dalam pelaksanaannya tidak terlepas dari dua dharma yang lain serta melibatkan segenap sivitas akademik: dosen, mahasiswa, tenaga kependidikan. Pengabdian kepada masyarakat ke SD, SMP, SMA Kasih Immanuel Jakarta Timur bertujuan untuk memberikan makna kebermanfaatan keberadaan Program Magister Administrasi Pendidikan kepada masyarakat pada umumnya dan Sekolah Kasih Immanuel Jakarta Utara pada khususnya 


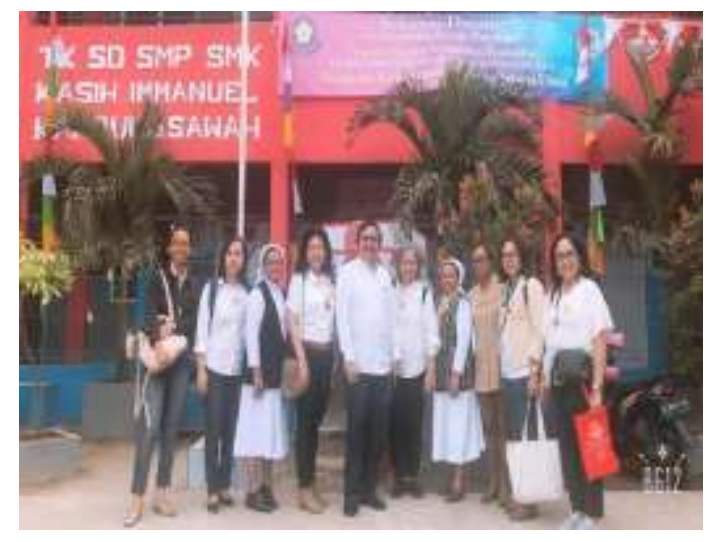

Gambar 1. Tim PKM Program Magister

Administrasi Pendidikan UKI terdiri dari dosen, mahasiswa, dan tenaga kependidikan

Pengabdian Kepada Masyarakat melalui kegiatan BIMTEK Implementasi Kurikulum 2013 bertujuan untuk:

1. Memberikan pengetahuan dan memperluas wawasan guru terkait dengan regulasi pendidikan terkait dengan kualifikasi pendidikan guru, kompetensi guru dan kurikulum 2013

2. Memberikan contoh implementasi Kurikulum 2013 pada pendekatan saintifik

3. Memberikan contoh silabus dan RPP sesuai dengan Kurikulum 2013 (Revisi 2018)

4. Memotivasi guru agar melaksanakan pembelajaran secara profesional.

Sebelum melaksanakan kegiatan pengabdian kepada masyarakat, terlebih dahulu dilakukan studi pendahuluan. Studi pendahuluan dengan metode survey ke SD, SMP, SMA Kasih Immanuel, dengan melakukan wawancara mendalam terhadap Kepala
Sekolah SD dan SMA dan Guru bertujuan untuk melakukan analisis kebutuhan sekolah. Adapun langkah-langkah yang dilakuakan sebagai berikut:

1. Melakukan dan menyusun rancangan program yang sesuai dengan kebutuhan sekolah dan relevan dengan bidang ilmu Prodi Administrasi Pendidikan.

2. Melakukan pelatihan peningkatan kompetensi guru bagi guru SD, SMP, dan SMA

Melakukan evaluasi pelatihan dan dampak bagi sekolah dan dijadikan dasar dalam melakukan pelatihan secara berkelanjutan.

1. Studi awal dengan metode survey ke SD, SMP, SMA Kasih Immanuel, bertujuan untuk melakukan analisis kebutuhan sekolah. Data diperoleh dengan wawancara mendalam terhadap Kepala Sekolah SD dan SMA dan Guru.

2. Melakukan dan menyusun rancangan program yang sesuai dengan kebutuhan sekolah dan relevan dengan bidang ilmu Prodi Administrasi Pendidikan.

3. Melakukan pelatihan peningkatan kompetensi guru bagi guru SD, SMP, dan SMA

4. Melakukan evaluasi pelatihan dan dampak bagi sekolah dan dijadikan dasar dalam melakukan pelatihan secara berkelanjutan 


\section{Populasi dan Sampel}

Cara pemilihan responden dengan sampel jenuh, artinya seluruh populasi menjadi sampel. Populasi 15 orang guru, namun pada saat kegiatan PkM yang hadir hanya 12 orang. Seluruh guru merangkap guru SD, SMP dan SMA.

\section{Alat/Bahan yang digunakan}

Alat/bahan yang digunakan untuk kegiatan pengabdian kepada masyarakat adalah materi presentasi dalam bentuk power point, instrumen test (pre test dan pos test) dan juga contoh RPP mata pelajaran Biologi, Kimia, dan Matematika SMP. Desain alat dikembangkan oleh narasumber dan fasilitator yang sesuai dengan bidangnya.

Kinerja dan produktivitasnya

Cara mengumpulkan data dengan mewawancarai mendalam kepala sekolah SD dan SMP. Selain itu juga dengan pre test dan post tes yang bertujuan untuk melihat kemampuan awal sebelum kegiatan BIMTEK dan peningkatan hasil setelah dilakukan BIMTEK.

\section{Analisis Data}

Analisis Data dengan menggunakan statistika deskriptif yang bertujuan untuk mendeskripsikan data guru berdasarkan jenis kelamin, kualifikasi akademik/pendidikan, jumlah guru yang sudah tersertifikasi dan kompetensi guru. Data disajikan dalam bentuk grafik untuk mempermudah memaknai data, dan dianalisis secara deskriptif

(Creswell,2007).

\section{HASIL DAN PEMBAHASAN}

Data hasil penelitian dideskripsikan berdasarkan (a) gender, (b) kualifikasi akademik guru, (c) sertifikasi guru, (d) kompetensi implementasi Kurikulum 2013 (sebelum dan setelah bimbingan teknis).

a. Deskripsi Guru Berdasarkan Gender.

Data guru berdasarkan jenis kelamin disajikan pada gambar 2

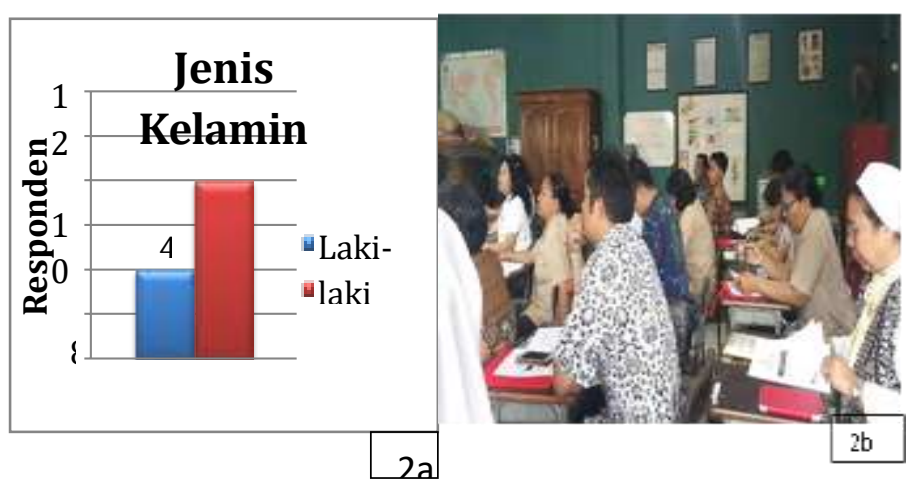

Gambar 2a dan 2b. Grafik data guru berdasarkan jenis kelamin

Berdasarkan gambar 2a. banyaknya responden 12 orang terdiri dari 4 Laki-Laki dan 8 perempuan. Pada umumnya guru di SD, SMP, SMA Kasih Immanuel adalah perempuan. Hal ini menunjukkan perempuan lebih menunjukkan keibuan dan tujuannya tidak saja untuk mengajar namun lebih dekat dengan siswa seperti anaknya sendiri. Berdasarkan hasil wawancara yang kami lakukan terhadap kepala sekolah dan guru, anak-anak yang bersekolah di SD, SMP, dan SMA Kasih Immanuel adalah anak yang tidak memiliki orangtua dan mereka tinggal di Panti 
Asuhan. Selain itu adalah siswa pindahan dari sekolah lain karena di sekolah asal siswa tersebut bermasal

b. Deskripsi Guru Berdasarkan Kualifikasi Pendidikan

Data guru berdasarkan kualifikasi pendidikan disajikan pada gambar 3 .

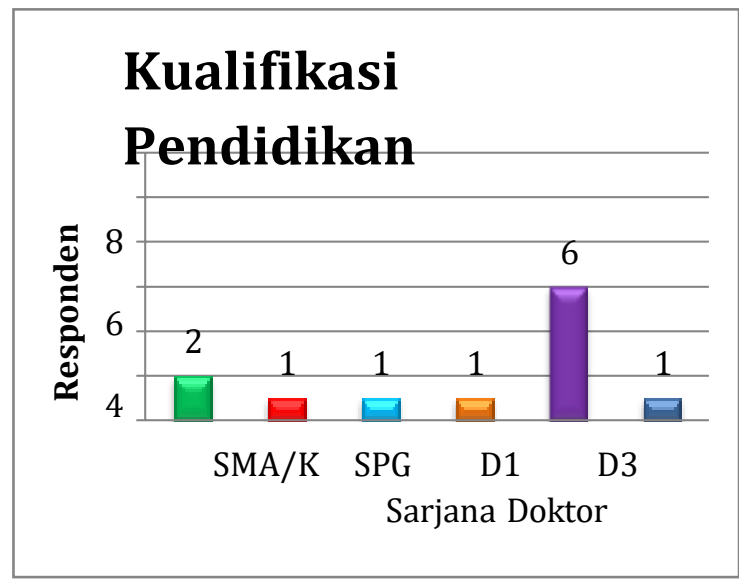

Gambar 3. Kualifikasi pendidikan guru

Gambar 3 menujukkan, jumlah guru di Sekolah Kasih Immanuel sebagai responden 12 orang. Guru di Sekolah Kasih Immanuel 1 orang Doktor, 6 orang Sarjana, 1 orang D3, 1 orang D1, dan 3 orang masih SMA/K. Berdasarkan UU No. 14 tahun 2015 yang menyatakan kualifikasi pendidikan guru minimal D4 atau Sarjana. Artinya 7 (58,3\%) yang sudah memenuhi regulasi dan 41,7\% yang belum memenuhi persyaratan. Saat ini ada 2 orang guru yang sedang on going program sarjana. Kepala sekolah terus mendorong agar guru mau kuliah namun keterbatasan dana. Guru mendapat gaji hanya dana dari BOS dan persembahan kasih para donatur. c. Deskripsi Guru Berdasarkan Sertifikasi Guru

Data guru berdasarkan sertifikasi pendidik disajikan pada gambar 4

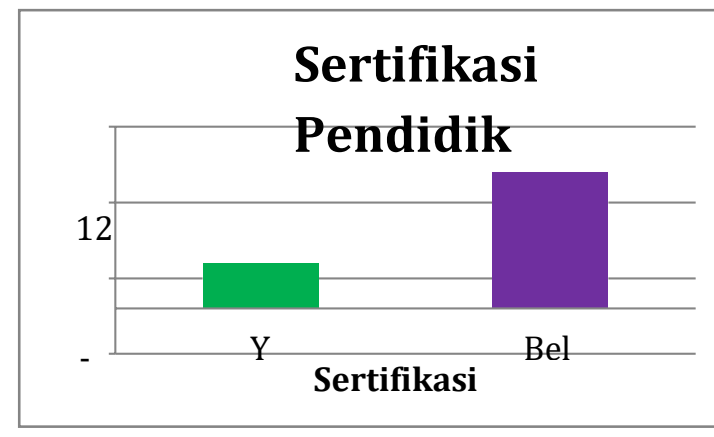

Gambar 4 Data Banyaknya guru yang tersertifikasi pendidik

Dari gambar 4 dapat menunjukkan, dari 12 guru yang menjadi responden ada 3 (25\%) guru sudah tersertifikasi. Berdasarkan wawancara yang mendalam guru menuturkan merasakan dampak tunjangan sertifikasi guru. Karena gaji dari Yayasan sangat minim dibawah upah minimum regional. Bagi guru yang memiliki keluarga dan anak tiga terasa berat menyekolahkan anak sampai $\mathrm{SMA} / \mathrm{K}$.

d. Deskripsi Guru Berdasarkan Kompetensi implementasi Kurikulum 2013.

Data guru berdasarkan kompetensi implementasi Kurikulum 2013 disajikan dalam gambar 5 . 


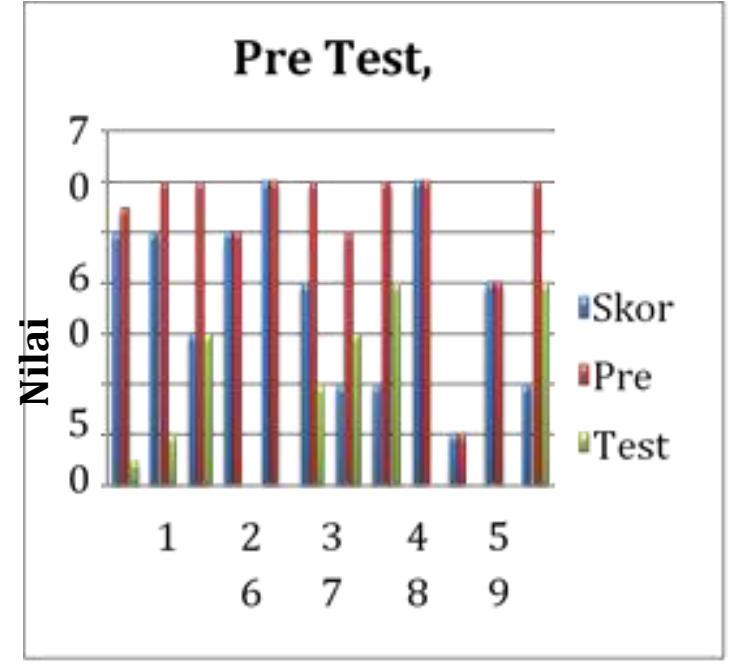

Gambar 5 Skor pre test, post test dan gain kompetensi guru

Gambar 5 menujukkan, kompetensi guru dalam mengimplementasikan Kurikulum 2013 masih rendah, ditunjukkan dengan hasil pre test yang dilakukan. Terdapat empat responden yang pre dan post test sama. Selama Bimtek guru kurang termotivasi karena kualifikasi pendidikannya belum memenuhi standar. Setelah dilakukan juga bimbingan teknis ada perubahan namun tidak signifikan. Berdasarkan hasil analisis butir dari instrumen implementasi kurikulum 2013 yakni konsep kurikulum 2013 khusus regulasi masih kurang dipahami. Hal ini terjadi karena guru belum semua ikut sosialisasi implementasi kurikulum 2013. Guru sangat merasakan manfaat dari kegiatan PkM karena dengan demikian guru memperoleh wawasan tentang landasan pendidikan. Guru belum semuanya mendapat kesempatan sosialisasi implementasi kurikulum 2013 yang diselenggarakan oleh pemerintah masih terbatas bagi kepala sekolah. Guru mengimplementasikan kurikulum 2013 berdasarkan pengalaman mengajar yang sudah lebih 10 tahun

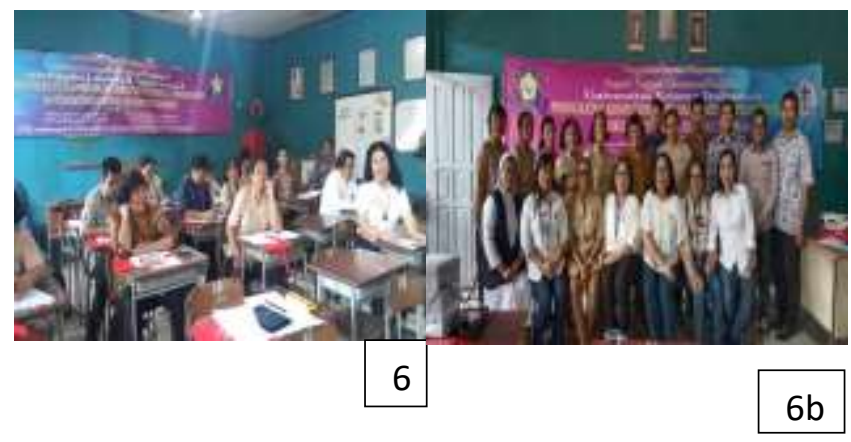

Gambar 6a. Suasana pre test dan $6 \mathrm{~b}$ selesai post test

Implikasi dari temuan memberikan motivasi kepada guru untuk melengkapi perencanaan pembelajaran (RPP). Semula guru kurang termotivasi melengkapi RPP bahkan melakukan pemutahiran sehingga RPP sesuai dengan aturan dan lengkap $100 \%$. Selain itu juga memotivasi guru agar meningkatkan kompetensi dalam mengetahu regulasi sehingga guru yang belum memenuhi standar guru maka meningkatkan kualifikasi dengan studi lanjut mengambil program sarjana pendidikan. Dengan lengkapnya RPP turut membantu kelengkapan dokumen dalam rangka akreditasi sekolah.

\section{KESIMPULAN}

Berdasarkan survey pendahuluan dan pelaksanaan kegiatan kepada masyarakat di Sekolah Kasih Immanuel dapat disimpulkan:

Guru di Sekolah Kasih Immanuel 
merangkap mengajar di SD, SMP, dan SMA

1. Jumlah Guru di Sekolah Kasih Immanuel sebanyak 14 orang namun yang ikut kegiatan BIMTEK Implementasi Kurikulum 2013 melalui PkM Prodi Administrasi Pendidikan Program Pascasarjana UKI hanya 12 orang dan 2 orang berhalangan.

2. Kualifikasi Pendidikan Guru yang sudah memenuhi regulasi minimal D4 atau sarjana hanya 7 orang dari 14 orang.

3. Terdapat 3 orang responden yang sudah tersertifikasi pendidik, dan merasakan manfaat tunjangan yang diperoleh. Profesionalitas seorang guru belum terlihat dengan nyata.

4. Pemberian BIMTEK Implementasi Kurikulum 2013 sangat dirasakan manfaatnya memberikan wawasan tentang landasan pendidikan agar menjadi guru profesional.

\section{UCAPAN TERIMA KASIH}

Pertama-tama peneliti mengucapkan rasa syukur kepada Tuhan Yang Mahakuasa karena Tim PkM dapat menyelesaikan penulisan Laporan PkM yang berjudul Peningkatan Kompetensi Guru Dalam Mengimlementasikan Kurikulum 2013 Dalam Education 4.0. PkM dapat terlaksana karena mendapatkan dukungan dari Universitas Kristen Indonesia. Ucapan terima kasih kami sampaikan kepada Dr. Aartje Tehupeiory,
$\mathrm{SH}, \quad \mathrm{MH}$ sebagai Kepala Lembaga Penelitian dan Pengabdian Masyarakat, Dr. Bintang R. Simbolon, M.Si. sebagai Direktur Program Pascasarsarjan, Dr. Dra. Mesta Limbong, M.Psi sebagai Kaprodi Magister Administrasi Pendidikan. Kami juga mengucapkan terima kasih kepada Pdt. Dr. Ir. Anike M. salaka, M.Pd, MA selaku kepala sekolah yang telah menerima kami dan dapat mengkoordinir kegiatan di Sekolah Kasih Imanuel. Tak lupa kami mengucapkan terima kasih kepada Saudara Rinto Situmorang, Sr. Modesta, dan Sr. Getrusis Mahasiswa Program Magister Administrasi Pendidikan. Akhirnya kepada semua pihak yang telah membantu baik dalam persiapan dan pelaksanaan PkM. Semoga Tuhan yang Maha Pengasih membalas baik budi bapak/saudara/i sekalian dan Sekolah Kasih Immanuel dapat mengimplementasikan dan mutu sekolah meningkat.

\section{PENUTUP}

Pengabdian kepada Masyarakat merupakan salah satu Tri Dharma Perguruan Tinggi dan wajib serta harus dilaksanakan demi peningkatan kualitas dosen dan mutu pendidikan di Universitas Kristen Indonesia.

\section{DAFTAR PUSTAKA}

Creswell. 2007. Qualitative Inquiry And Research Design. London New Delhi: SAGE Publications Cruickshank $D, R$, et.al. (2014). The act of teaching. San Francisco: Mc Graw Hill 
Miri , et all. Purposely Teaching for the Promotion of Higher-order Thinking Skills: A Case of Critical Thinking. Volume 37, Research in science education. Issue 4, pp 353-369

Hopson,M.H,.Simms R.L., Knezek G.A., Using a Technology-Enriched Environment to Improve HigherOrder Thinking Skills. Journal of research on technology in education, vol 34, 2001, issue 2

Pedoman Pelaksanaan Pengabdian Kepada Masyarakat (PkM) Universitas Kristen Indonesia. LPPM UKI: 2018

Peraturan Pemerintah No. 74 tahun 2008 tentang Guru

Peraturan Menteri Pendidikan Nasional nomor 16 Tahun 2007 mengatur kompetensi guru untuk setiap satuan pendidikan 
